\title{
Multimodalidade da linguagem nas campanhas de prevenção HIV/Aids: uma análise cognitiva e cultural
}

\author{
Language multimodality in HIV/Aids prevention campaigns: \\ a cognitive and cultural analysis
}

\author{
Sheila Rocha \\ Heloísa Pedroso de Moraes Feltes
}

Universidade de Caxias do Sul - UCS - Caxias do Sul - Rio Grande do Sul - Brasil

\begin{abstract}
Resumo: O objetivo deste artigo é analisar e comparar a linguagem multimodal em campanhas de prevenção HIV/Aids, concentrando-se, principalmente, na perspectiva da Linguística Cognitiva, incorporando a abordagem de fatores regionais, culturais e identitários, implicados na produção dessas campanhas. Para isso, também investigam-se as diretrizes apontadas por políticas públicas de saúde no Brasil, em especial ao caso da Aids, e como o marketing social atua para a criação de melhores condições de vida para todos, utilizando a publicidade como uma ferramenta de propagação desses conceitos. Para atender a essa proposição, o corpus é formado por três cartazes de campanhas publicitárias lançadas em diferentes regiões do país. A investigação fundamenta-se na Teoria da Metáfora Conceitual, proposta por George Lakoff, Mark Johnson e autores associados, bem como nos estudos sobre multimodalidade, desenvolvidos, especialmente, por Charles Forceville. Através deste estudo, conclui-se que as metáforas/metonímias verbais e visuais evidenciam traços regionais, culturais e identitários, aproximando a linguagem do seu público-alvo e salientando especificidades que acionam o processo perceptivo dos receptores, contribuindo para a eficácia de mensagens que estimulam a mudança de hábitos e comportamentos.
\end{abstract}

Palavras-chave: Campanhas de Prevenção HIV/Aids; Multimodalidade; Metáfora; Metonímia e Modelos Culturais.

Abstract: This article aims to introduce and discuss epistemologically the design of a research methodology on the processes for interpreting metaphors in literay texts in the interface with the product, i.e., their multiple readings. The research motivation, from the beginning, was investigating what 'metaphor' really means to the 'empirical reader', thus contributing to elucidate the social and cognitive processes that may occur during its interpretation. The methodology adopted is qualitative, with an interpretive orientation. The main method, whose construction process is the major focus of this paper, is Group-Think Aloud, which is derived from an adaptation of the Verbal Protocol. This method is associated with diaries and interviews, to enable the triangulation of data. To investigate whether there is variation in the processes and readings of 'metaphor', it became necessary to generate data with various groups of readers, thus constituting a collective case study as research strategy. This methodological design falls within the interpretive paradigm, whose epistemology is that of dialogism.

Keywords: HIV/Aids Prevention Campaigns; Multimodality; Metaphor; Metonymy and Cultural Models. 


\section{Introdução}

De acordo com dados do Ministério da Saúde ${ }^{1}$, a Aids $^{2}$ - Síndrome da Imunodeficiência Adquirida (Acquired Immune Deficiency Syndrome) - é causada pelo vírus HIV (Human Immunodeciency Virus), que ataca as células de defesa do corpo, deixando o organismo vulnerável a diversas doenças, de um simples resfriado a infecções mais graves como tuberculose ou câncer. O vírus, que é transmitido através de relações sexuais desprotegidas, pela transfusão de sangue, pelo compartilhamento de seringas contaminadas ou de mãe para filho (gravidez e amamentação), tornou-se uma verdadeira epidemia em meados dos anos 1980. Algum tempo após o surgimento da epidemia, foram criados medicamentos para controlar o desenvolvimento da Aids, que ajudaram a prolongar a vida de seus portadores. Entretanto, segundo as informações divulgadas pela Organização Mundial de Saúde ${ }^{3}$, em outubro de 2013, mais de 36 milhões de pessoas já morreram e ainda existem cerca de 35 milhões de pessoas infectadas pelo vírus em todo o mundo. Por isso, a prevenção é tão importante para que a epidemia possa ser controlada.

Em causas como a da Aids, a publicidade atua para exercer um dos seus papéis menos valorizados, mas também um dos mais ilustres, que é o de despertar um desejo, não o de consumo, mas sim, o de proteger a própria vida. Este artigo utiliza campanhas sociais de prevenção ao vírus da Aids como objeto de estudo da linguagem, destacando justamente as relações que ela exerce com a cultura em que está inserida. A partir dessa questão, objetivamos investigar, sob a ótica da Linguística Cognitiva, a multimodalidade da linguagem e as

\footnotetext{
1 Dados retirados do portal sobre Aids, doenças sexualmente transmissíveis e hepatites virais, do Governo Federal. Disponível em: <http://www.aids.gov.br/pagina/o-que-e-aids>.

2 Optamos por usar neste artigo a forma 'Aids', somente com a inicial em caixa alta, porque é uma sigla que pode ser lida silabicamente. Além disso, evitamos conceder um 'peso' ainda mais assustador à epidemia, que estaria representado visualmente por todas as iniciais com letras maiúsculas. Entretanto, mantemos a forma 'AIDS', quando assim utilizada pelos autores citados.

${ }^{3}$ Informações obtidas no site da OMS. Disponível em: <http://www.who.int/mediacentre/factsheets/fs360/es/index.html $>$ Acesso em: 20 jul. 2014.
}

possíveis diferenças regionais/culturais que garantem a eficácia de campanhas publicitárias voltadas à prevenção de HIVIAids.

\section{HIV/Aids no BRASIL: políticas públicas de saúde, regionalização e construção de identidades}

As políticas de prevenção, controle e tratamento de HIVIAids adotadas no Brasil tiveram grande êxito. Isso porque o país foi um dos pioneiros a utilizar um coquetel de medicamentos, distribuído gratuitamente à população infectada. De acordo com Mônica Malta e Francisco Bastos, o Brasil "desenvolve ações abrangentes de prevenção desde o início da epidemia e oferece acesso a qualquer cidadão brasileiro às terapias antiaids mais modernas, o que é garantido por lei federal desde 1996." (2012, p. 933).

Atualmente, existem cerca de 21 medicamentos antirretrovirais, que são distribuídos de forma gratuita à população em postos de saúde, clínicas e hospitais públicos. Novos desafios, entretanto, deverão surgir no futuro. Malta e Bastos advertem que podem existir dificuldades "tanto no manejo clínico destes pacientes quanto com as implicações financeiras de manter um contingente cada vez maior de pacientes recebendo medicamentos mais caros e complexos através do SUS". (2012, p. 952).

As estratégias adotadas também sofrem 0 impacto das diferenças geográficas, que acabam gerando condições distintas para o acesso, quantidade e disponibilidade dos programas antiaids. Para Bastos, as camadas mais pobres e desfavorecidas "não encontram meios de se proteger de forma consistente, às voltas que estão com outras necessidades prementes, como ter o que comer, arranjar um local para dormir ou mesmo arranjar meios de adquirir a próxima pedra de crack que irão fumar." (2006, p. 85). O autor explica que diversos pesquisadores brasileiros vêm encontrando essa dinâmica no país: "as inúmeras e profundas fissuras da sociedade brasileira têm dado lugar a epidemias 
de cunho local ou mesmo regional, ainda que, no conjunto, a epidemia brasileira esteja, grosso modo, estabilizada." (BASTOS, 2006, p. 87).

Nesse contexto, as campanhas publicitárias são fundamentais para o controle da epidemia, através de informações que contribuam para o entendimento social e a necessidade de evitar qualquer forma de discriminação.

\section{Marketing social e campanhas de HIVIAids}

De acordo com Philip Kotler e Nancy Lee, o marketing social difere-se do tradicional marketing comercial porque ele tem um objetivo puramente social: "refere-se fundamentalmente a esforços focados em influenciar comportamentos que vão melhorar a saúde, evitar acidentes, proteger o meio ambiente e contribuir para as comunidades em geral". (2011, p. 26). Os autores reforçam essa ideia dizendo que "o marketing social é um processo que aplica princípios e técnicas de marketing para criar, comunicar e proporcionar valor a fim de influenciar comportamentos". (2011, p. 26).

O marketing atua com um conjunto de processos, entre os quais está a propaganda/publicidade. Philip Kotler define propaganda ${ }^{4}$ como sendo "qualquer forma de apresentação impessoal e de promoção de ideias, bens ou serviços, paga por um patrocinador identificado." (1994, p. 538).

Nos anos 1980, quando iniciavam os primeiros casos de Aids no Brasil, o governo procurava, através da propaganda e do controle dos meios de comunicação, apresentar uma determinada visão

\footnotetext{
${ }^{4}$ Neste trabalho, optamos por adotar a expressão publicidade, já que os termos 'publicidade' e 'propaganda' são usados no Brasil, na maioria das vezes, indistintamente, representando definições similares. O que queremos expressar aqui, nesta dissertação, são as interfaces exercidas pela publicidade em seu contexto linguístico, cultural e social. De acordo com Armando Sant'Anna, "publicidade deriva de público, e designa a qualidade do que é público. Significa o ato de vulgarizar, de tornar público um fato, uma ideia. Propaganda é definida como a propagação de princípios e teorias, compreende a ideia de implantar, de incluir uma ideia, uma crença na mente alheia." O autor segue explicando que "comercialmente falando, anunciar visa promover vendas e para vender é necessário, na maior parte dos casos, implantar na mente da massa uma ideia sobre o produto. Contudo hoje ambas as palavras são usadas indistintamente." (1996, p. 75).
}

sobre a doença. José Ricardo Ayres (2002), que fez um apanhado sobre as lições aprendidas das práticas preventivas e sobre os desafios atuais impostos pela doença, afirma que a primeira lição é de que o terrorismo não funciona. Nos primeiros anos da epidemia, as campanhas apresentavam argumentos que estabeleciam o terror e o medo na população, porém esse tipo de apelo não resultou na mudança de comportamento almejada.

Nascimento reitera que "a cada ano, slogans diferentes propõem basicamente uma coisa: o uso da camisinha na relação sexual” (1997, p. 173). Porém, ela acredita que "independente do acúmulo de conhecimento acerca da doença, as campanhas sofrem visíveis avanços e retrocessos em sua capacidade de transmitir informações claras e isentas de preconceitos." (1997, p. 173).

\section{Linguística cognitiva e multimodalidade da linguagem: modelos cognitivos e culturais}

A Linguística Cognitiva, ao relacionar mente e corpo na construção de sentidos, traz à tona elementos fundamentais entre a linguística e a comunicação, analisando nossa concepção de mundo, nossa cultura e nossa interação com as pessoas.

De acordo com as definições de George Lakoff, nós organizamos nosso conhecimento através de estruturas mentais, as quais ele denomina de Modelos Cognitivos Idealizados. Para Lakoff (1987, p. 68), cada Modelo Cognitivo Idealizado é um complexo estruturado, uma gestalt, que está constituído pelos seguintes princípios: estruturas proposicionais (formada por Proposição Simples, Cenário ou Script, Feixe de Traços, Taxonomia e Categorias Radiais); esquemas imagéticos (classificados pelo autor por: CONTAINER, ORIGEM-PERCURSO-META, LIGAÇÃO, PARTE-TODO, PARA CIMA-PARA BAIXO, FRENTE-TRÁS); mapeamento metafórico e mapeamento metonímico.

Dentro desse novo paradigma, as metáforas passam a ser reconhecidas por seu valor cognitivo. Nas palavras de Lakoff e Johnson, "a metáfora está 
infiltrada na vida cotidiana, não somente na linguagem, mas também no pensamento e na ação. Nosso sistema conceptual ordinário, em termos do qual não só pensamos mas também agimos, é fundamentalmente metafórico por natureza." (2002, p. 45). ${ }^{5}$

Para exemplificar como a metáfora está presente em nosso cotidiano, os autores demonstraram como nós vivenciamos uma discussão em termos de uma guerra. Eles apresentam o conceito discussão pela metáfora conceptual DISCUSSÃO É GUERRA com os seguintes exemplos:

Seus argumentos são indefensáveis. (Your claims are indefensible.)

Ele atacou todos os pontos fracos da minha argumentação. (He attacked every weak point in my argument.)

Suas críticas foram direto ao alvo. (His criticisms were right on target.)

Destruí sua argumentação. (I demolished his argument.)

Jamais ganhei uma discussão com ele. (I've never won an argument with him.) (LAKOFF; JOHNSON, 2002, p. 46)

Os pesquisadores denominam esse tipo de metáfora como conceptual, justamente por representar e sistematizar os conceitos que estabelecemos em nossa linguagem e pensamento. Para representar essa estrutura, Lakoff e Johnson (2002) utilizam, em letras maiúsculas, a seguinte sistematização: DOMíNIO-ALVO É DOMíNIOFONTE, fazendo um mapeamento entre os dois conceitos utilizados na metáfora. No exemplo já citado, temos a GUERRA como o DOMÍNIO-FONTE e a DISCUSSÃO como expressão do DOMíNIO-ALVO.

Assim como a metáfora, a metonímia também é um recurso que vai muito além de traduzir apenas um estilo poético ou retórico, mas representa uma função importante em nosso processo cognitivo. Lakoff e Johnson afirmam que a metonímia possui a mesma sistematicidade da metáfora. Os autores acreditam que "quando pensamos em um Picasso,

\footnotetext{
${ }^{5}$ A obra Metaphors we live by foi traduzida para o português no ano de 2002, com o título Metáforas da Vida Cotidiana, pelo Grupo de Estudos da Indeterminação e da Metáfora (GEIM), sob coordenação de Mara Sophia Zanotto e pela tradutora Vera Maluf.
}

não estamos pensando apenas em uma obra de arte: mas estamos também pensando na relação dessa obra com o artista, isto é, a sua concepção de arte, sua técnica, seu papel na história da arte." (2002, p. 96).

Para Charles Forceville, uma metáfora não pode ser analisada apenas pela sua forma verbal, pois isso pode constituir uma visão limitada. É por essa razão que passa a ser extremamente importante uma investigação mais ampla, não apenas do que está sendo escrito, mas também do que está sendo mostrado através da imagem e do que não está sendo dito, mas fica implícito no contexto.

Forceville desenvolve a ideia de que a diferença entre a metáfora multimodal e a monomodal (que estaria centrada apenas na linguagem verbal) está no "modo". O autor propõe a seguinte divisão para a interpretação da linguagem multimodal: "(1) signo pictórico; (2) signo escrito; (3) signo falado; (4) gestos; (5) sons; (6) música; (7) cheiros; (8) gostos; (9) toque." (2009, p. 23). A proposta da metáfora multimodal, que analisa um texto sob diferentes ângulos - e não apenas no plano prototípico da metáfora, que é a forma verbal - nos permite analisar como imagem e texto atuam de forma complementar, auxiliando na construção do sentido.

As experiências cotidianas, que estão fortemente ligadas aos valores apreendidos de uma determinada cultura, originam nossa estruturação metafórica. Roger Kessing (1987, p. 370) faz uma abordagem sobre como as metáforas convencionais despertaram grande interesse no estudo da antropologia cognitiva e modelos culturais. Ele apresenta os estudos das metáforas convencionais feitos por Lakoff e Johnson através de uma visão da linguagem baseada em termos que são usados na nossa maneira de falar todos os dias, ou seja, na nossa experiência. De acordo com essa teorização, vemos que as metáforas só terão sentido se fizerem parte do contexto de um determinado sistema social, no qual as pessoas constroem seus discursos a partir daquilo que sabem para a significação do seu próprio mundo.

Na sua análise sobre as metáforas da cultura, 
Kövecses conclui que existe uma ligação estreita entre as metáforas e os modelos culturais. Segundo ele, "os modelos culturais são importantes em nossas tentativas de descrever e caracterizar o sistema conceptual humano e, portanto, as culturas." (2005, p. 193). O autor descreve os modelos culturais como os melhores meios de conceber as organizações coerentes da experiência humana, compartilhadas entre as pessoas.

\section{Método, procedimentos e análise do corpus}

Nesta investigação, desenvolvemos uma pesquisa qualitativa a partir de corpus multimodal (e.g., MITTELBERG, 2007), composto por três campanhas de prevenção de HIV/Aids lançadas por órgãos de saúde públicos em regiões brasileiras distintas. A análise visa comparar os recursos da linguagem multimodal (verbal e não verbal) utilizados e a realidade de cada cultura, às quais as campanhas nos remetem.

Para análise do corpus desta pesquisa é seguido o modelo desenvolvido por Feltes e Gambin (2012) e Gambin (2014). Nesse padrão, extraímos de cada peça seus elementos pictóricos e verbais, estabelecendo Frames $^{6}$ que separam os aspectos cognitivos, culturais e regionais de cada unidade que compõe o corpus do presente trabalho.

O procedimento de análise desenvolvido obedece aos seguintes passos: seleção do corpus; tratamento do corpus (isolando graficamente os elementos que compões as peças escolhidas); análise de modelos cognitivos metafóricos e metonímicos; análise de padrões regionais e de modelos culturais.

\section{ANÁLISE DO CORPUS}

\section{Sem camisinha não dá - CAR1}

De acordo com as informações do Ministério da Saúde ${ }^{7}$, a campanha, lançada para os festejos de carnaval de 2011, foi direcionada a mulheres na faixa etária de 15 a 24 anos, das classes C, D e E. A campanha, assinada pelo SUS, pela Secretaria de Políticas para as Mulheres e pelo Ministério da Saúde, teve por objetivo incentivar a adoção do uso do preservativo entre as garotas e, para aquelas que desconhecem seu status sorológico para o HIV, informa sobre a praticidade, gratuidade e confidencialidade do exame de Aids, sífilis e hepatite viral.

Figura 1 - Sem camisinha não dá - CAR1

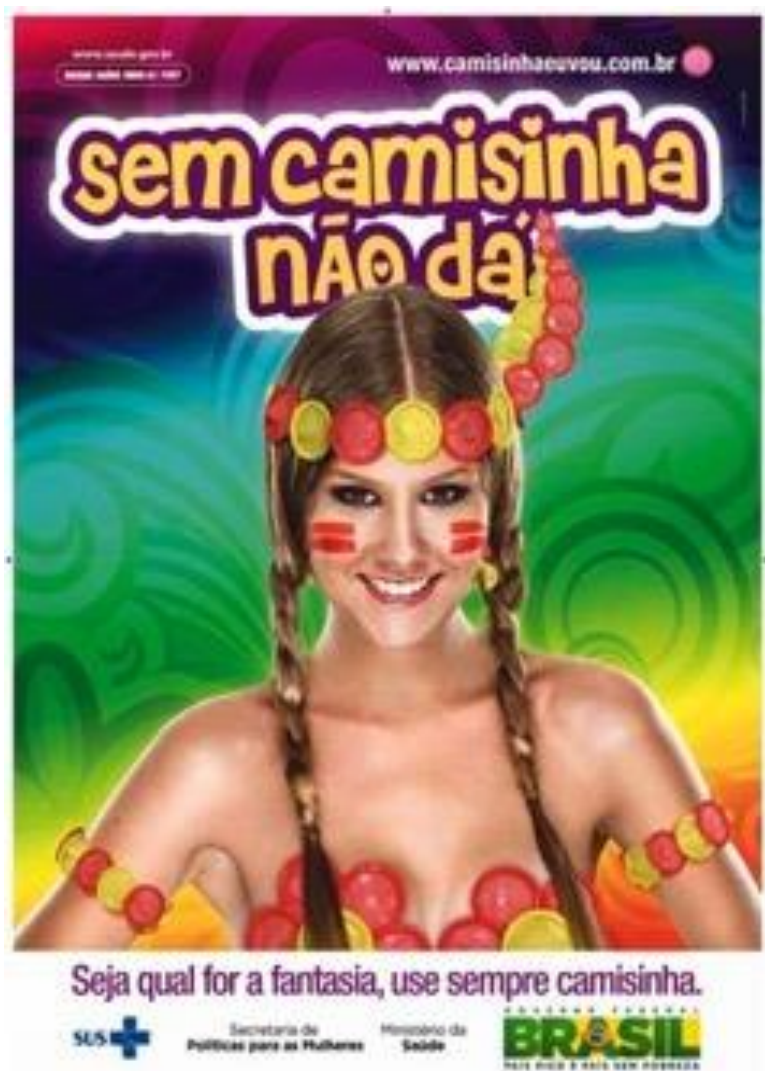

Fonte: http://www.aids.gov.br/campanha/carnaval-2011

\footnotetext{
${ }^{6} \mathrm{O}$ termo 'Frames' usado nesta análise se refere ao recorte de imagens e textos através de software de edição de imagens, diferentemente dos constructos frames, que são, de acordo com a Linguística Cognitiva, modelos cognitivos proposicionais.
} 
Quadro 1 - Decomposição do cartaz - CAR1

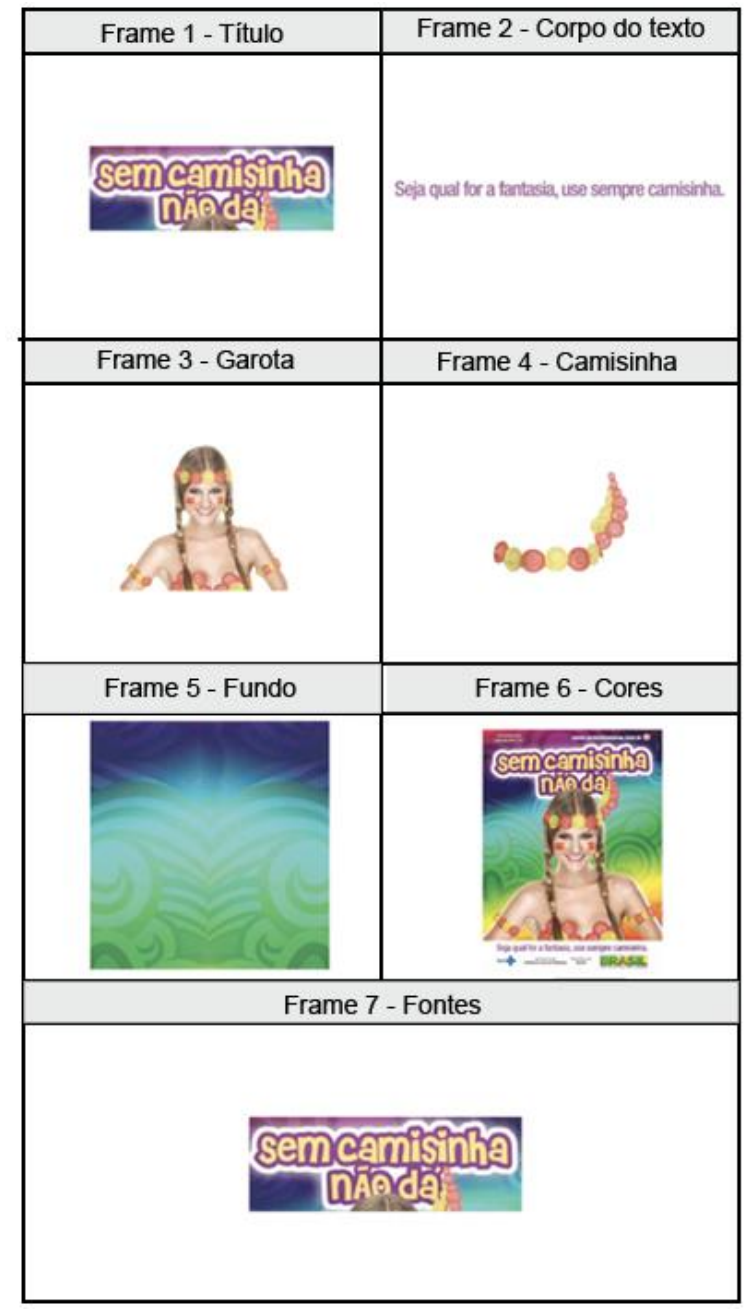

Fonte: Quadro adaptado de Rocha (2015, p. 90)

\section{a) Análise do modo verbal}

No Frame CAR1-1, observando a chamada principal "Sem camisinha não dá", propositalmente ambígua, tem-se as seguintes interpretações:

- Metáfora que parte do domínio-fonte de entregar algo a alguém. Nesse caso, o domínio-alvo é entregar o próprio corpo. A expressão "dar" é amplamente compartilhada por adolescentes como sinônimo de aceitar e praticar o ato sexual. A chamada principal explora esse modelo cultural, enfatizando o "não dá". Ou seja, o ato sexual é uma doação, que só pode ser feita se for com o uso de camisinha.

- O enunciado também designa um mapeamento metonímico ao relacionarmos uma parte do corpo pelo todo. Nesse caso, ao associarmos ao ato sexual, as partes envolvidas são, mais especificamente, os genitais.
- Neste cartaz, podemos inferir a seguinte metáfora conceitual: O CORPO E SUAS PARTES SÃO OBJETOS que podem ser entregues ou partilhados com alguém.

- A expressão também parece ressaltar o poder feminino, que tem em suas mãos a opção de apenas seduzir - mas não ceder aos apelos masculinos. 0 verbo 'poder', nesse caso, significa 'não deve'. Nesse sentido, a chamada é ambígua, sendo comunicados simultaneamente dois significados: Não faça sexo (não dê seu órgão genital) sem camisinha e Sem camisinha não deve haver sexo.

No Frame CAR1-2 observamos o seguinte texto: "Seja qual for a fantasia, use sempre camisinha". No enunciado, a "fantasia" apresenta duplo sentido: tanto se refere à fantasia carnavalesca, vestimentas comumente utilizadas para esse tipo de festa, reforçada pela imagem, como à fantasia erótica, relacionada ao ato sexual.

\section{b) Análise do modo não verbal}

$\mathrm{Na}$ imagem central da campanha (Frame CAR1-3) o que mais chama a atenção é o fato de ser uma garota muito jovem, que aparece com o peito nu, coberto apenas por camisinhas. Um olhar mais atento nos mostra que a moça está com uma fantasia de carnaval: seus cabelos em trança, o adorno na cabeça, a pintura no rosto e a roupa (simbolizada pelas camisinhas) referem-se à vestimenta de uma mulher de tribo indígena.

No carnaval, as fantasias são usadas como forma de transgressão. Stuart Hall, ao fazer uma abordagem sobre as metáforas de transformação para pensar a cultura, teoriza sobre essa noção de transgressão, afirmando que "o carnaval é a metáfora da suspensão e inversão temporária e sancionada da ordem, um tempo em que o baixo se torna alto e o alto, baixo, o momento da reviravolta, do 'mundo às avessas"” (HALL, 2013, p. 247).

$\mathrm{Na}$ imagem da jovem, portanto, fica evidente uma projeção do carnaval como domínio-fonte, representando o domínio-alvo da transgressão sexual. A expressão da garota também tem duplo sentido: passa ingenuidade e, ao mesmo tempo, 
sedução.

O uso das camisinhas coloridas, destacadas no Frame CAR1-4, como adornos da fantasia da garota, está ligado ao fato de a camisinha ser um elemento-chave para a proteção. Nessa projeção visual, metonimicamente, a camisinha ganha um novo símbolo de proteção ao corpo feminino.

No Frame CAR1-5, a textura do fundo acompanha a linguagem juvenil e carnavalesca da peça. Os efeitos reproduzem o formato das camisinhas, através de arabescos em forma de círculos. Esse fundo também parece reforçar a ideia de clima quente, alegórico e carnavalesco.

A escolha das cores do cartaz, reproduzido no Frame CAR1-6, reforça a ideia de carnaval, em uma ampla gama de tonalidades bastante acentuadas e impactantes. Essas cores fortes representam um ambiente quente, como seria o ambiente carnavalesco.

A fonte principal, que aparece no Frame CAR17 também introduz novas possibilidades de leitura. Por um lado, é marcante, apresenta uma sombra carregada e contrastante. De outro, é jovial e descontraída, com seu formato bem arredondado e corações para representar os sinais de acentuação. Trata-se de uma característica muito juvenil e feminina.

\section{Xamêgo bom, só com camisinha! - CAR2}

A campanha de prevenção a doenças sexualmente transmissíveis, em especial a Aids, foi lançada pela Secretaria Municipal de Saúde de Campina Grande, no dia 07 de junho de 2013, durante os festejos juninos. ${ }^{8}$ A ideia foi conscientizar a população para o uso do preservativo nas relações sexuais, com mensagens inspiradas na literatura de cordel. A Coordenação Municipal de DST, Aids e Hepatites Virais montou uma tenda de serviços no local da festa - Parque do Povo - para realização de atividades interativas com o público. Analisaremos o cartaz que foi criado para essa campanha.

Figura 2 - Xamêgo bom, só com camisinha - CAR2

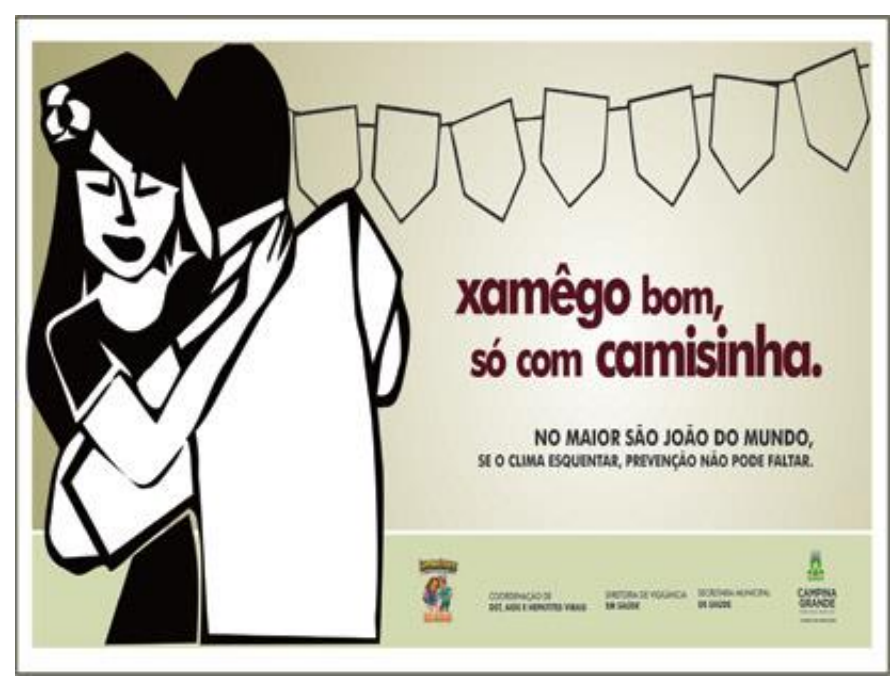

Fonte: http://campinagrandepb.com.br/campanha-deprevencao-as-dst-e-aids-vai-distribuir-mais-de-500-milpreservativos-no-sao-joao/

Quadro 12 - Decomposição do cartaz - CAR2

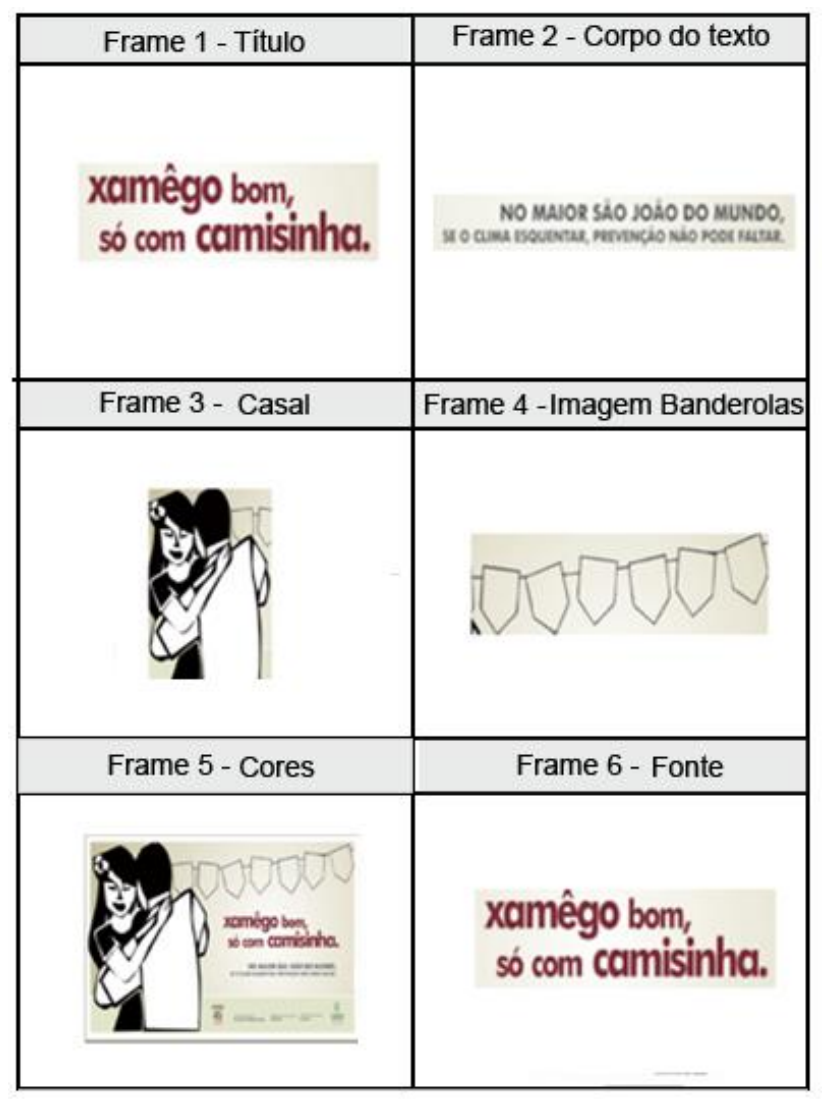

Fonte: Quadro adaptado de Rocha (2015, p. 80)

\footnotetext{
8 Informações retiradas do site http://campinagrandepb.com.br/campanha-de-prevencao-asdst-e-aids-vai-distribuir-mais-de-500-mil-preservativos-no-saojoao/. Acesso em: 26 abr. 2015.
} 


\section{a) Análise do modo verbal}

O título principal, reproduzido no Frame CAR21, faz uso de um termo regional nordestino: "xamêgo". A expressão é usada para definir "namoro, atração, carinho". Além disso, Nunes e Souza (2014, p. 24), observam que:

\begin{abstract}
Algumas palavras que são frequentemente usadas e em cujo som há a presença especial do fonema [ $\mathrm{S}$ ], permeando todo um conjunto de canções com um "chiado" que alude ao arrastar dos pés na dança. Por exemplo, fazem parte deste grupo as palavras chiadas: xote, xodó, chamego, xaxado, chinelo, riacho, remelexo, paixão, apaixonado, chuva, chorar, chororô, Lua-cheia, cachaça, avexar.
\end{abstract}

Nesse enunciado do cartaz, o termo aparece de maneira errônea. Como vimos na citação de Nunes e Souza, em sua grafia original, o termo é escrito com "ch" e também não leva acento, já que trata-se de uma paroxítona: chamego. É possível que o redator da campanha tenha se equivocado ou que a utilização fora da regra foi usada propositadamente com o objetivo de caracterizar a fala local e se aproximar ainda mais da cultura popular representada pelo forró.

No enunciado principal, observa-se a existência de um processo de metonimização. Nessa relação, podemos interpretar que o SEXO SÓ É BOM SE FOR SEGURO, ou que TODO CARINHO É MELHOR QUANDO SE TEM PROTEÇÃO. Dessa forma, trata-se de um processo de metonimização em que "xamêgo", como contato físico com conotação carinhosa, é o que leva, em geral, ao ato sexual, numa relação CAUSA-CONSEQUÊNCIA.

O corpo do texto, descrito no Frame CAR2-2, contém a seguinte descrição: "No maior São João do Mundo, se o clima esquentar, prevenção não pode faltar". Nesse texto, temos uma metáfora que parte do domínio-fonte de TEMPERATURA CLIMÁTICA para o domínio-alvo de TEMPERATURA CORPORAL. Essa associação se refere à sensação corporal numa relação romântica/sexual. A representação do clima quente é utilizada para definir o desejo sexual, fazendo uma associação com a temperatura corporal que também se eleva nas pessoas que mantém contato físico ou amoroso. Podemos representar essa metáfora como a ATRAÇÃO FísICA É CALOR. Essa relação conceitual também possui base num princípio metonímico, pois o calor é um dos efeitos gerados pelo corpo nessa situação de envolvimento sexual. Poderíamos citar outros como: palpitação cardíaca, vermelhidão, êxtase, entre outros. Esse processo foi descrito por Lakoff (1987) quando trata do modelo radial de RAIVA, mas que se aplica a outras emoções metaforicamente expressas como FLUIDO NUM RECIPIENTE.

\section{b) Análise do modo não verbal}

A imagem do casal, em destaque no Frame CAR2-3, reforça o apelo do clima quente, reproduzido na linguagem verbal. Pela posição do casal, pode-se deduzir que eles estejam dançando forró, um ritmo típico das festas nordestinas. Nunes e Souza investigaram o forró como um movimento cultural popular, nascido no Nordeste nos anos 1940. Os autores afirmam que "a temática reúne menções, principalmente, sobre o universo rural sertanejo e sobre o momento em que acontece o forró, entendido como festa, com todas as suas implicações a respeito das conquistas amorosas no instante da dança". (2014, p. 22).

A representação visual da peça utiliza ilustrações feitas com inspiração na literatura de cordel, que foi trazida pelos portugueses e se tornou popular na região nordeste. No caso desse cartaz, porém, essa inspiração se reflete mais diretamente nas tonalidades em preto e branco e nos traços fortes, representativos dos cordéis, que eram livretos simples, impressos em tipografia, com baixo custo de produção. Essa ilustração do cartaz, entretanto, não simboliza a representação do cordel prototípico, que apresentava o cangaço, a seca, o trovadorismo. Temos um casal romântico, em que o homem aparece de costas: é o coadjuvante. A mulher é quem aparece de frente e em destaque. Mas é uma mulher romantizada, bem distante, por exemplo, da personagem Maria Bonita, a mais prototípica do 
cangaço.

Assim, percebemos uma forte ligação regional do cartaz analisado com a cultura nordestina, caracterizando-se por uma peça de forte cunho persuasivo na região em que está inserida. Além disso, a peça incorpora elementos da cultura e da arte para a publicidade, enriquecendo seu conteúdo.

As bandeirolas que aparecem no Frame CAR2-4 são um elemento adicional da imagem, servindo como plano de fundo para o ambiente junino. No Frame CAR2-5, as cores usadas são neutras e seguem, como já foi mencionado, o padrão cromático em preto e branco, fazendo uma referência ao padrão da literatura de cordel. As fontes, no Frame CAR4-6, apresentam formas simples e de fácil leitura.

\section{Eu sou um cartaz HIV Positivo - CAR3}

A campanha de mídia impressa e urbana foi criada para a ONG Grupo de Incentivo à Vida (GIV), utilizando cartazes que contêm uma gota de sangue de portadores do HIV. Não há risco de contaminação pelo sangue dos cartazes, já que o vírus não sobrevive por mais de uma hora fora do corpo. O objetivo foi alertar quanto à importância de dizer não ao preconceito. A mensagem principal é reforçada pelo conceito: "Se o preconceito é uma doença, a informação é a cura". Além dos cartazes, foi produzido um vídeo mostrando a recepção da campanha nas ruas. ${ }^{9}$
Figura 3 - Eu sou um cartaz HIV Positivo - CAR3

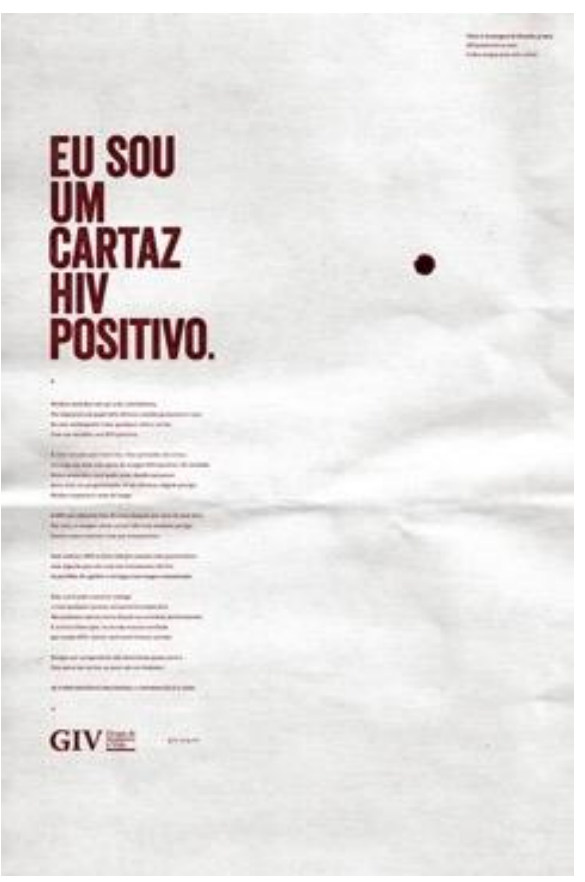

Fonte: Imagem enviada por Teresinha Martins, assessora do GIV - Grupo de Incentivo à Vida - e voluntária da campanha.

Quadro 3 - Decomposição do cartaz - CAR3

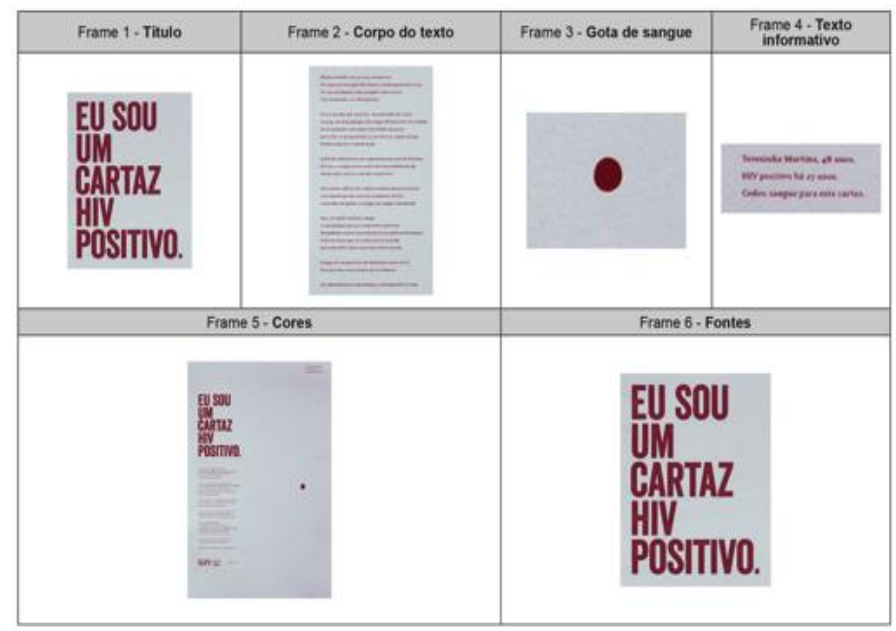

Fonte: Quadro adaptado de Rocha (2015, p. 119)

\section{a) Análise do modo verbal}

Este cartaz diferencia-se das demais peças do corpus desta pesquisa, em primeiro lugar, porque é apresentado em All-Type, ou seja, Só Texto. Rafael Sampaio faz a seguinte explanação sobre o termo: "no caso dos anúncios, é aquele esquema de uso apenas de texto, sem imagens complementares (ou com imagens mínimas), sendo o texto geralmente decorrente de um título." (2003, p. 43). Neste caso, a

\footnotetext{
9 As informações foram coletadas de diferentes sites que divulgaram o lançamento da campanha. São eles: $<$ http://www.ogilvy.com.br/\#!/noticias>; $<$ https://queminova.catracalivre.com.br/educacao/cartaz-hivpositivo-combate-preconceito-nas-ruas-de-sp/> 
utilização de praticamente apenas um modo da linguagem contribui para o impacto da peça. Outro fator inusitado neste último cartaz é que o único elemento ilustrativo do layout é uma gota de sangue, que foi coletada de pessoas reais, HIV positivas, que participaram voluntariamente da campanha.

No título apontado pelo Frame CAR3-1 "Eu sou um cartaz HIV Positivo" chama a atenção o fato de que o cartaz é tratado como uma pessoa. O uso dessa metáfora como um recurso da campanha, pode ser explicado com a afirmação de Sandmann de que: "a personificação tem também a função de causar estranhamento, de prender o leitor." (2012, p. 90). O autor cita o seguinte exemplo: “'A rua que não dorme.' dizia folheto de propaganda da Rua 24 Horas, de Curitiba, em que se pode ver também uma metonímia ou uma, transferência por associação espacial: quem não dorme, na verdade, são os vendedores e os compradores." (2012, p. 90). No caso do Cartaz HIV Positivo há também um processo metonímico, em que o cartaz está representando cada um dos voluntários reais que participam da campanha.

O corpo do texto também apresenta um traço diferenciado dos demais: é mais extenso que o usual para este tipo de material. Esse texto foi separado no Frame CAR3-2, mas como a imagem recebida estava em baixa resolução e não apresenta uma leitura adequada, reproduzimos abaixo o texto completo do cartaz:

"Eu sou um cartaz HIV positivo. Minhas medidas são $40 \times 60$ centímetros.

Fui impresso em papel Alta Alvura e minha gramatura é 250 .

$\mathrm{Eu}$ sou exatamente como qualquer outro cartaz.

Com um detalhe: sou HIV positivo.

É isso mesmo que você leu. Sou portador do vírus.

Carrego em mim uma gota de sangue HIV positivo. De verdade.

Neste momento, você pode estar dando um passo

para trás se perguntando se eu ofereço algum perigo.

Minha resposta é: nem de longe.

O HIV não sobrevive fora do corpo humano por mais de uma hora.

Por isso, o sangue neste cartaz não traz nenhum perigo.

Assim como conviver com um soropositivo.

Você contrai o HIV se tiver relações sexuais sem preservativos com alguém que não está em tratamento efetivo,

se partilhar de agulhas e seringas com sangue contaminado.

Sim, você pode conviver comigo

e com qualquer pessoa soropositiva numa

boa.

Nós podemos exercer nossa função na sociedade perfeitamente.

$\mathrm{E}$ arrisco dizer que, se eu não tivesse revelado

que tenho HIV, talvez você nem tivesse notado.

Porque ser soropositivo não determina quem você é.

Seja para um cartaz ou para um ser humano.

Se o preconceito é uma doença, a informação é a cura." 10

O corpo do texto começa com o cartaz falando sobre si mesmo e suas características. Esse recurso da humanização, muito usado em publicidade, é citado por Marina Negri como uma figura de linguagem que se mostra "capaz de intensificar emoções, de assustar e até enternecer, quando, por exemplo, coisas e animais de quaisquer espécies falam, pensam e possuem habilidades não naturais." (2011, p. 133). Nesse caso, temos um cartaz que se autointitula HIV Positivo, causando impacto na mensagem.

No decorrer da narrativa, o texto vai fazendo comparações entre o sangue contido no cartaz e uma pessoa real, que é soropositiva, numa projeção metonímica, em que o sangue do cartaz representa a pessoa. Todo o descritivo faz um diálogo com o leitor, trazendo informações importantes sobre a doença e as formas de contágio. A última frase do enunciado, que também conceitua a campanha, constitui-se de um continuum metonímia-metáfora, cujo frame é INFECÇÃO POR HIV. O último enunciado expressa duas metáforas importantes: PRECONCEITO É DOENÇA e INFORMAÇÃO É CURA.

A gota que aparece no Frame CAR3-3 foi feita com o sangue dos voluntários, portadores de HIV. Essa representação é entendida como uma projeção

\footnotetext{
10 O texto foi enviado por Teresinha Martins, do Grupo de Inventivo à Vida. Teresinha foi uma das voluntárias que cedeu seu sangue para a campanha. A informação que recebemos de Teresinha é que ela ainda não possuía a imagem em alta resolução, que servirá para impressão e distribuição, dessa forma, o texto completo veio separadamente da imagem. Essa transcrição do texto completo também pode ser encontrada no site: http://propmark.uol.com.br/agencias/53345:ogilvy-espalhacartaz-hiv-positivo. Acesso em: 04 maio 2015.
} 
metonímica em que a gota representa a pessoa portadora do vírus. Essa simbologia também pode ser traduzida como uma metáfora que apresenta o seguinte mapeamento: apesar de uma pessoa ser portadora do vírus, esse sangue, isoladamente, não é capaz de transmitir a doença para outra pessoa. Então, o sangue, que a maioria das pessoas vê com medo, não oferece perigo. O texto explica que só é possível contrair a doença mantendo relações sexuais sem proteção com pessoas portadoras do vírus que não estejam em tratamento efetivo, ou compartilhando seringas com sangue contaminado. Dessa forma, pode-se concluir que a convivência e o contato físico com um portador do vírus não oferece perigo. Essa metáfora, portanto, traduz o conceito de que o PORTADOR DO VÍRUS NÃO É PERIGOSO. O que oferece mais perigo é o preconceito.

O Frame CAR3-4 destaca um texto informativo, que caracteriza a identidade da pessoa voluntária que cedeu seu sangue. No modelo contido neste artigo, o texto apresenta o seguinte enunciado: "Teresinha Martins, 48 anos. HIV Positivo há 27 anos. Cedeu sangue para este cartaz.". Com essa informação, o cartaz é associado a uma pessoa real e amplia seu poder de persuasão.

As cores e fontes usadas no cartaz, evidenciadas nos Frames CAR3-5 e CAR3-6 são clássicas e contrastantes, em um layout igualmente clean e elegante, tudo para destacar, a partir de conceitos minimalistas, a importância que carrega esta mensagem. O vermelho, a cor do sangue, é a que aparece com mais evidência.

\section{Conclusões}

Neste artigo, foi possível situar, ainda que brevemente, aspectos importantes para a sistematização e promoção da saúde no Brasil, em especial ao caso da Aids, que obteve no país um modelo de ação eficaz para o controle da epidemia, tratamento e qualidade de vida dos seus portadores.

Através do marketing social, um tipo de marketing que se difere do comercial, pois não possui fins lucrativos, busca-se moldar esta disciplina para a criação de melhores condições de vida para todos. Dentro do mix de marketing, a publicidade atua como uma ferramenta para a promoção de conceitos criativos em diferentes canais de comunicação, com o objetivo de persuadir seu público-alvo.

A linguagem persuasiva, estratégica para as campanhas publicitárias, foi analisada a partir da Linguística Cognitiva, através da multimodalidade da linguagem, escolha que pode ser considerada bastante assertiva para a análise deste corpus. Forceville (1996) aponta a publicidade como um meio eficaz para a compreensão das metáforas multimodais. O autor avalia que "um anúncio tem um objetivo inequívoco: vender ou promover um produto ou serviço. Se esta intenção central não for encontrada, o anúncio falhou. A publicidade tem, portanto, um grande interesse comercial em ter suas intenções reconhecidas." ${ }^{11}$ (1996, p. 65). Dessa forma, o autor entende que a publicidade fornece um corpus que permite a identificação de importantes modelos para a análise, pois o domínio-alvo precisa estar ligado ao produto anunciado.

Outro ponto investigado foi justamente as implicações regionais, culturais e identitárias que formam a linguagem das peças. Foi possível comprovar como as metáforas verbais e visuais conectam-se à cultura em que estão inseridas. Traços regionais foram utilizados no cartaz "Xamêgo bom, só com camisinha". Campanhas de veiculação nacional também fazem uso de especificidades da cultura para chamar a atenção dos receptores das mensagens. Citamos o exemplo do cartaz "Sem camisinha não dá", que explora um perfil de público bem distante daquele que era discriminado como pertencente ao grupo de risco da doença. A garota do cartaz é uma adolescente de cor branca e muito jovem. E, finalmente, campanhas como o "Eu sou um cartaz HIV Positivo" desmistificam a identidade criada pela doença, influenciado os leitores a mudarem seu ponto de vista sobre o preconceito em relação aos portadores do vírus.

\footnotetext{
${ }^{11}$ Do original: "An advertisement has an unambiguous purpose: to sell or promote a product or service. If this central intention does not come across, an advertisement has failed. Advertising thus has a great commercial interest in having its intentions recognized."
} 
Com base neste estudo, concluímos que a linguagem multimodal tem um papel fundamental para a construção dos discursos, auxiliando a estabelecer relações positivas, não apenas com relação à proteção, mas também estimulando novas formas de olhar para a doença, desvinculando-se de preconceitos. A publicidade, nestes casos, assume um novo papel persuasivo, contribuindo para a qualidade de vida das pessoas e provocando um outro tipo de consumo: o dos modelos positivos.

Ainda há muito a ser feito para garantir uma ação eficaz no controle do vírus. Segundo vimos, a Aids prolifera-se, especialmente, em centros urbanos, aproveitando-se da vulnerabilidade causada pela falta de recursos. Os grandes cinturões de pobreza concentram a maior parte dos novos casos da doença. Entretanto, Bastos é quem alerta: "qualquer ideia de sexo absolutamente seguro esbarra no contra-senso de uma certeza absoluta em um mundo de incertezas e probabilidades." (2006, p. 50).

O pesquisador também declara que "o pânico provocado pelas epidemias costuma despertar o que há de melhor e de pior em cada um de nós". (BASTOS, 2006, p. 95). Certamente, de acordo com o autor, novas epidemias farão parte da vida, consequência de constantes mudanças climáticas, da devastação sistemática de nossos ecossistemas e de todas as suas implicações, dados que parecem carregar previsões apocalípticas para o futuro. Restanos, então, a esperança de que possamos enfrentálas de um modo mais humano e livre de preconceitos.

\section{Referências}

AYRES, José Ricardo C. Mesquita. Práticas educativas e prevenção de HIV/Aids: lições aprendidas e desafios atuais. Interface Comunicação, Saúde, Educação. v. 06, n. 11, p. 11-24, 2002. Disponível em: <http://dx.doi.org/10.1590/S141432832002000200002>. Acesso em: 26 jul. 2014.

BASTOS, Francisco Inácio. Aids na terceira década. Rio de Janeiro: Editora Fiocruz, 2006. 104 p. (Temas em Saúde).

FELTES, Heloísa P. de M; GANBIM, Aline. Metáforas e metonímias multimodais na comunicação publicitária: posicionamento da marca Polar e projeção da imagem da organização. In: GOMES, Languisner; FELTES, Heloísa P. de M. (org). Entre mesclas e metáforas: nos labirintos da geração do sentido. Caxias do Sul: Educs, 2012. p. 243-265.

FORCEVILLE, Charles. Pictorial metaphor in advertising. London e New York: Routledge, 1996.

FORCEVILLE, Charles; Non-verbal and multimodal metaphor in a cognitivist framework: Agendas for research. In: FORCEVILLE, Charles; URIOS-APARISI, Eduardo. Multimodal metaphor. New York: Mouton De Gruyter, 2009. p. 19-42.

GAMBIN, Aline. O regional na comunicação publicitária: o posicionamento identitário da marca Polar. 2014. 138 f. Dissertação (Mestrado) - Universidade de Caxias do Sul, Programa de Pós-Graduação em Letras, Cultura e Regionalidade, 2014. Disponível em: $\quad<$ http://hdl.handle.net/11338/868>. Acesso em: 20 abr. 2015.

HALL, Stuart. Da diáspora: identidades e mediações culturais. Org. Livik Sovik. 2. ed. Belo Horizonte: Editora UFMG, 2013.

KESSING, Roger M. Models, "folk" and "cultural": paradigms regained? In: HOLLAND, Dorothy; QUINN, Naomi. Cultural models in language and thought. New York: Cambridge University Press, 1987. p. 369-394.

KOTLER, Philip. Administração de Marketing: análise, planejamento, implementação e controle. 4. ed. São Paulo: Atlas, 1994.

KOTLER, Philip; LEE, Nancy. Marketing social. Influenciando comportamentos para o bem. 3. ed. Porto Alegre: Bookman, 2011.

KÖVECSES, Zoltán. Metaphor in culture: universality and variation. Cambridge University Press, 2005.

LAKOFF, George. Women, fire, and dangerous things: what categories reveal about the mind. Chicago: The University of Chicago Press, 1987.

LAKOFF, George; JOHNSON, Mark. Metáforas da vida cotidiana. (Coordenação da tradução: Mara Sophia Zanotto). Campinas, São Paulo: Mercado de Letras; São Paulo: Edpuc, 2002.

MALTA, Mônica; BASTOS, Francisco Inácio. Aids: prevenção e assistência. In: GIOVANELLA, Lígia; ESCOREL, Sarah; LOBATO, Lenaura C. V.; NORONHA, José C.; CARVALHO, Antonio. (Org.). Políticas e sistema de saúde no Brasil. 2. ed. Rio de Janeiro: Editora Fiocruz, 2012. p. 933-957. 
MITTELBERG, Irene. Methodology for multimodality: one way of workin with speech and gesture data. In: Methods in cognitive linguistics. Gonzales-Marques, Monica; Mittelberg, Irene. John Benjamins Publishing: Amsterdan, 2007.

NASCIMENTO, Dilene R. A face visível da Aids. História, Ciências, Saúde-Manguinhos. Rio de Janeiro, v. 4, n.1, Junho 1997. Disponível em: $\quad$ http://dx.doi.org/10.1590/S010459701997000100009. em: 29 jan. 2015.

Acesso

NEGRI, Marina. Contribuições da Língua Portuguesa para a redação publicitária. São Paulo: Cengage Learning, 2011.

NUNES, El-Buainin V. M.; SOUZA, Santinho F. O forró e suas configurações: a aliteração, a mulher, o homem, o movimento corporal e o ambiente nas canções forrozísticas. Revista Entrelinhas, v. 8, n.1, p.21-28, jan/jun. 2014.

ROCHA, Sheila. Campanhas de prevenção HIV/Aids: multimodalidade da linguagem e modelos culturais. 2015. 151 f. Dissertação (Mestrado) - Curso de Pós-Graduação em Letras, Cultura e Regionalidade, Universidade de Caxias do Sul, Caxias do Sul, 2015.

SAMPAIO, Rafael. Propaganda de $A$ a Z. 3 ed. Rio de Janeiro: Elsevier, 2003.

SANDMANN, Antônio. A linguagem da propaganda. 10. ed. São Paulo: Contexto. 